\title{
High-Resolution Pore-ScAle Water CONTENT MEASUREMENT IN A TRANSLUCENT SOIL PROFILE FROM LIGHT TRANSMISSION
}

\author{
E. Orozco-López, R. Muñoz-Carpena, B. Gao, G. Fox
}

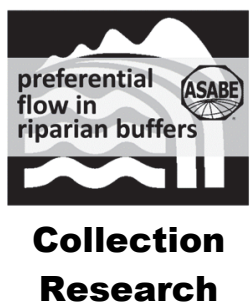

\begin{abstract}
HighLIGHTS
- Research methods are needed to study preferential flow processes at pore scale and high temporal resolution.

- Novel verification of the light transmission method shows high efficiency to measure rapid transient soil water flow.

- Recast of a previous physical model allows reliable pore-scale water content quantification in translucent soil profiles.

- Insights from the light transmission method can inform preferential flow modeling efforts.
\end{abstract}

\begin{abstract}
Understanding rapid transient flows in the soil unsaturated zone continues to be a major challenge in hydrology and water quality engineering. For example, surface runoff mitigation by riparian buffers can be limited by rapid transient flows due to the natural propensity of these areas for preferential flow pathways (i.e., caused by roots, wormholes, or wetting/drying cycles). However, current monitoring technologies are limited in their ability to capture rapid soil preferential flows at high spatial and temporal resolutions. Among the state-of-the-art technologies to monitor preferential flow, the light transmission method (LTM) has become a promising tool to quantify pore-scale water contents at a laboratory scale, but its reliability and consistency need further study. The objectives of this study are to recast a previously developed LTM physical model, propose a novel verification method to assess LTM reliability to measure pore-scale water dynamics in laboratory translucent soil profiles, and identify the representative pore radius of translucent soil profiles based on their average number of pores. This study found a high measuring efficiency with LTM for soil moisture and drainage estimations (NSE $>0.98, R M S E<5.4 \%$ ), showing its potential for use in laboratory analysis of pore-scale rapid transient water dynamics typically found in preferential flow through the vadose zone. This study also shows that the parameter traditionally associated with the number of pores in a translucent soil profile is a fitting parameter with no direct physical meaning.
\end{abstract}

Keywords. Beer-Lambert law, Fresnel law, Light transmission method, Preferential flow, Riparian buffer, Vadose zone.

$\mathrm{A}$ variety of hydrologic systems are significantly influenced by the presence of subsurface preferential flow pathways. To date, hydrologists commonly use lumped Darcian flow approaches to indirectly account for such preferential flow processes, but such approaches limit our ability to accurately predict the impacts of preferential flow in many practical situations. For example, effective use of riparian buffers and vegetative filter strips as runoff mitigation strategies for nutrients, pesticides, and bacteria requires an understanding of the dominant surface and subsurface flow and transport processes

Submitted for review on 1 September 2020 as manuscript number NRES 14292; approved for publication as a Research Article and as part of the Preferential Flow and Piping in Riparian Buffers Collection by the by the Natural Resources \& Environmental Systems Community of ASABE on 18 January 2021.

The authors are Enrique Orozco-López, Graduate Student, Rafael Muñoz-Carpena, Professor, and Bin Gao, Professor, Department of Agricultural and Biological Engineering, University of Florida, Gainesville, Florida; Garey Fox, Professor, Department of Biological and Agricultural Engineering, North Carolina State University, Raleigh, North Carolina. Corresponding author: Rafael Muñoz-Carpena, Frazier Rogers Hall, University of Florida, Gainesville, FL 32611-0570; phone: 352-294-6747; e-mail: carpena@ufl.edu.
(Fox et al., 2018; Lauvernet and Muñoz-Carpena, 2019; Muñoz-Carpena and Parsons, 2004; Muñoz-Carpena et al., 1999, 2018). However, these areas are highly susceptible to preferential flow due to their intense biogeochemical activity (Orozco-López et al., 2018; Fox, 2019). Recent research identifies macropores as pervasive preferential flow pathways for dissolved and colloidal pollutants in riparian areas, where high rainfall/runoff rates lead to higher macropore activation, resulting in faster contaminant transport (Carlyle and Hill, 2001; Fuchs et al., 2009; Jarvis, 2007; Lambrechts et al., 2014; Menichino et al., 2014; Orozco-López et al., 2018). However, while theoretical modeling frameworks are available for preferential flow processes, there is a dearth of experimental and modeling techniques to characterize macropore flow processes at pore, soil profile, and landscape scales (Beven, 2018; Orozco-López et al., 2018). Novel measurement and computational data analysis techniques provide opportunities to address still unsolved macropore flow questions at pore scale (Jarvis et al., 2016).

The need to develop detailed insights on water flow and contaminant transport processes in the soil vadose zone has led to the development of a variety of tools and methods to determine soil moisture from different signals. However, most of the existing technologies average the soil water 
content over a meso-scale sensing volume $\left(10^{2}\right.$ to $10^{3} \mathrm{~cm}^{3}$ or larger), and some are destructive or introduce artifacts into the soil matrix from the insertion of probes in the sensing domain (Muñoz-Carpena et al., 2005). While soil moisture sensing at this representative elementary volume (REV) scale is often adequate for macroscopic descriptions, such as those inherent in Darcian or capillarity-based approaches, new advances in understanding rapid transient flows among interphases in the soil vadose zone are limited by our ability to accurately measure pore-scale soil water content and fast transfer of water in fractures. For instance, the study of rapid transient flows such as those in preferential flow (Nimmo, 2010) is limited by the scale at which the measurements can be obtained. Quantifying the diffusion from the preferential flow pathway (i.e., macropore) into the surrounding soil matrix requires measurements at very high spatial and temporal resolutions. As a result, our ability to test alternative macropore flow theories depends on the measurability of the phenomena at the pore scale, i.e., the sensitivity of the sensor to capture sufficiently increasing moisture content from the macropores to the soil matrix at a very high resolution. Another example of increasing concern is the spills of nonaqueous liquids, such as petroleum derivatives, on soil surfaces, where the prediction of their fate and transport is also limited by the centimeter scale at which they can currently be measured (Simmons and Keller, 2005). Therefore, the need to capture and analyze pore-scale processes remains a challenge of great importance for unsaturated soil hydrology and contaminant transport studies, especially for pollution mitigation systems such as vegetation buffers.

Some of the non-contact high-resolution methods developed to estimate soil water content include, but are not limited to, x-ray (Rimmer et al., 1998; Tidwell and Glass, 1994), gamma ray (Oostrom et al., 2007), magnetic resonance imaging (MRI) (Haber-Pohlmeier et al., 2010; Hall et al., 1997), computed tomography (CT) (Heijs et al., 1996), and light transmission method (LTM) (Darnault et al., 2001; Hoa, 1981; Niemet and Selker, 2001; Niemet et al., 2002; Tidwell and Glass, 1994). While radiation methods (x-ray, gamma ray, MRI, and CT) provide measurements at high resolutions, their application is costly and often impractical because they require specialized personnel, facilities, and equipment. Light transmission through a translucent soil profile provides an attractive alternative to the radiation methods for analyzing transient vadose zone flows at very high resolution. For example, the LTM device used in this study operates at high spatial $(2048 \times 2048$ pixels, with a pixel size of $\left.0.3 \mathrm{~mm}^{2}\right)$ and temporal $(1 / 40 \mathrm{~s})$ resolutions, in contrast with commonly used dielectric methods, which integrate over a sensible volume of a few centimeters with a lower temporal scale on the order of seconds (Weiler and Naef, 2003). Provided that a fraction of the incident light is transmitted through a thin layer of porous media with variable fluid content, LTM can be used with liquids including water (Glass and Nicholl, 1996; Hoa, 1981; Niemet and Selker, 2001; Selker et al., 1992), saline solution (Weisbrod et al., 2002), liquid in non-aqueous phase (Alazaiza et al., 2016; Conrad et al., 2002; Darnault et al., 1998; Wang et al., 2008), colloidal solution (Weisbrod et al., 2003), and gases such as air in all the above references or $\mathrm{CO}_{2}$ (Bob et al., 2008; Glass et al., 2000).

As one of the pioneers in the theoretical and practical development of LTM, Hoa (1981) proposed to combine the physical laws of Beer-Lambert and Fresnel to quantify soil moisture from the attenuation of light through a thin layer of soil. Hoa's combined expression captures not only the light losses that occur through the soil phases based on the BeerLambert law but also the refractive losses that occur through the interphases based on the Fresnel law. However, Hoa's method relies on establishing an empirical relationship between light transmission and soil water content, making the approach semi-empirical. Many follow-up LTMs have been developed based on this initial approach to improve the parametrization and conceptual components (Bauters et al., 1998; Darnault et al., 1998; Glass et al., 1989; Tidwell and Glass, 1994; Wang et al., 2008). For example, Tidwell and Glass (1994) derived a semi-empirical expression following Hoa (1981) to determine water saturation from the light transmitted through porous media and proposed an empirically calibrated factor $(k)$ for the number of pores across the soil profile layer. Other LTM initiatives have focused on the development of fully physical approaches, requiring little or no calibration (Bob et al., 2008; Niemet and Selker, 2001; Selker et al., 1992). For instance, following Tidwell and Glass (1994), Niemet and Selker (2001) proposed an expression to obtain effective saturation from light intensity attenuation without empirical calibration requirements. However, Niemet and Selker (2002) identified that its application was limited due to their assumption of uniform-sized pores, contrary to the non-uniform pore size distribution of a typical soil.

The objective of this study is to test the efficiency of LTM to predict soil moisture at pore scale from the transmitted light intensity through a translucent soil profile. To achieve this objective, this study recasts the original Niemet and Selker (2001) equation to include a non-uniform pore size distribution and the changing conditions that the light encounters in variable moisture conditions. We experimentally evaluated the accuracy of this revised LTM approach using pore-scale soil water measurements. A novel method of experimental verification is proposed based on point measurements of emergent light intensity through translucent soil profile samples of known water content, supported by a physical method based on the Jurin law for direct estimation of the number of pores parameter.

\section{THEORETICAL FrAMEWORK \\ LIGHT TRANSMISSION EQUATIONS}

The LTM is based on the relationship between water content $\left(\theta, \mathrm{cm}^{3} \mathrm{~cm}^{-3}\right)$ and the intensity of light transmitted through a soil profile $(I)$, expressed as a relative index. Light attenuation between the input $\left(I_{\text {in }}\right)$ and output $(I)$ light through a sample is proportional to two characteristics of porous media: (1) the light absorption coefficient $\left(\alpha_{i}, \mathrm{~cm}^{-1}\right)$ of each phase $i$ (i.e., solid, liquid, and gas) contained in the sample, and (2) the corresponding phase thicknesses or optical paths $\left(d_{i}, \mathrm{~cm}\right)$. Figure 1 shows a conceptual scheme of the 


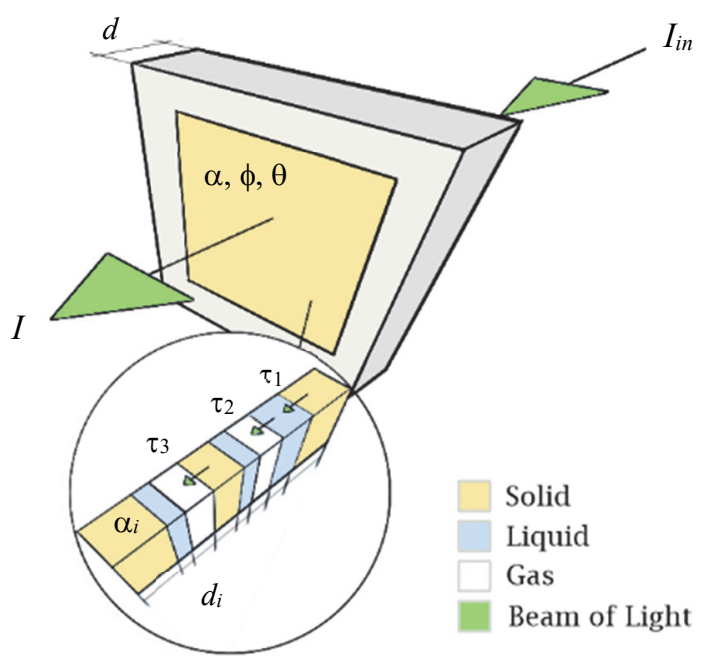

Figure 1. Conceptual scheme of parameters expressed in Beer-Lambert law and Fresnel law, where $I_{i n}$ is the light intensity of the source, $I$ is the intensity of light transmitted through the media, $d$ is the thickness of the sample (cm), $\alpha$ is the absorption coefficient of the sample $\left(\mathrm{cm}^{-1}\right), \phi$ is the porosity of the media $\left(\mathrm{cm}^{3} \mathrm{~cm}^{-3}\right)$, and $\theta$ is the water content of the sample $\left(\mathrm{cm}^{3} \mathrm{~cm}^{-3}\right)$. The enlarged inset represents a hypothetical path, formed by particles and fluids, that a beam of light could travel as it passes through the porous media, where $\tau_{1}, \tau_{2}$ and $\tau_{3}$ are the Fresnel transmission factors through the interphases $j=1: 3$ (solid-liquid, liquid-gas, and solid-gas), $\alpha_{i}$ is the absorption coefficient $\left(\mathrm{cm}^{-1}\right)$ of each individual phase $i=1: 3$ (solid, liquid, and gas), and $d_{i}$ is the thickness of each integrated phase through the sample $(\mathrm{cm})$.

parameters in the Beer-Lambert law. In addition to $\alpha_{i}\left(\mathrm{~cm}^{-1}\right)$ in each phase, losses occur due to refraction of light when passing through the interphases. There are three interphases $(j=1: 3)$ in variably saturated porous media: solid-liquid, liquid-gas, and solid-gas. The losses due to light transmission at the interphases ( $\tau_{j}$ in fig. 1$)$ are determined by the Fresnel law:

$$
\tau_{j}=\frac{4 n_{j}}{\left(n_{j}+1\right)^{2}}
$$

where $n_{j}$ is the quotient between the two refractive indices $\left(n_{a}\right.$ and $\left.n_{b}\right)$ of the phases that form the interphase $\left(n_{j}=n_{a} / n_{b}\right)$. The phases used in the porous media considered in this study are solid (sand), water, and air, with subscripts $s, w$, and $a$, respectively. Table 1 shows the refractive indices $\left(n_{a}\right.$ and $\left.n_{b}\right)$ of the individual components of each interphase, the refractive index $\left(n_{j}\right)$ of the interphase, and the corresponding transmission factor $\left(\tau_{j}\right)$.

By integrating the set of light losses through the total thickness of the porous media $(d, \mathrm{~cm})$, a combined expression of the Beer-Lambert and Fresnel laws is obtained (Hoa, 1981; Niemet and Selker, 2001):

Table 1. Possible interphases in porous media whose phases are sand, water, and air and their respective light transmission factors $\left(\tau_{j}\right) ; n_{a}$ and $n_{b}$ are the refractive indices of the individual components of interphase $\boldsymbol{j}$, whose refractive index is $\boldsymbol{n}_{j}$.

\begin{tabular}{cccccc}
\hline$j$ & Interphase & $n_{a}$ & $n_{b}$ & $n_{j}$ & $\tau_{j}$ \\
\hline 1 & Sand-water & 1.60 & 1.33 & 1.20 & 0.992 \\
2 & Water-air & 1.33 & 1.00 & 1.33 & 0.980 \\
3 & Sand-air & 1.60 & 1.00 & 1.60 & 0.947 \\
\hline
\end{tabular}

$$
I=I_{i n}\left(\Pi_{j=1}^{3} \tau_{j}^{2 k_{j}}\right) \cdot e^{\left(-\alpha_{i} d_{i}\right)}
$$

where $k$ is the total average number of pores that a beam of light finds in its path when passing through the variably saturated porous media, and $k_{j}$ represents the fraction of the pores in each interphase. Hoa (1981) proposed that each pore could be either completely full (solid-liquid interphase) or completely empty (solid-gas interphase) of water, where $p$ is the number of pores filled with water and so $k_{1}=p$ and $k_{3}=$ $k-p$, and assumes that there are no pores in the remaining interphase (liquid-gas) and so $k_{2}=0$. Therefore, the Fresnel transmission factors considered by Hoa (1981) are reduced to the sand-water $\left(\tau_{1}\right)$ and sand-air $\left(\tau_{3}\right)$ interphases:

$$
I=I_{\text {in }} \tau_{1}^{2 p} \tau_{3}^{2(k-p)} \cdot e^{\left(-\alpha_{s} d_{s}-\alpha_{w} d_{w}-\alpha_{a} d_{a}\right)}
$$

where the light absorption coefficients $\left(\alpha_{i}, \mathrm{~cm}^{-1}\right)$ correspond to water $\left(\alpha_{w}=10^{-4} \mathrm{~cm}^{-1}\right.$, Kröckel and Schmidt, 2014), air $\left(\alpha_{a} \approx 0\right)$, and sand $\left(\alpha_{s}=0.2 \mathrm{~cm}^{-1}\right.$, Lee et al., 2017). The light absorption coefficients of water $\left(\alpha_{w}, \mathrm{~cm}^{-1}\right)$ and air $\left(\alpha_{a}, \mathrm{~cm}^{-1}\right)$ may be considered negligible compared to that of sand $\left(\alpha_{s}, \mathrm{~cm}^{-1}\right)$ and removed from equation 3 . The limitation of this initial work was the empirical fitting of parameter $p$ to obtain a function of water content with light intensity. Tidwell and Glass (1994) expressed the Hoa (1981) equation in terms of water saturation $(S)$ instead of $p$ by introducing the relationship $p=S k$ in equation 3 . Following this, Niemet and Selker (2001) proposed a physical expression to obtain point effective saturation $\left(S_{e}\right)$ as a function of the emergent light through the media without calibration. To this end, they assumed wet media above residual soil moisture conditions, with uniform-sized pores and water films clinging to the pore interstitial area and individual drainage of pores:

$$
S_{e}=\frac{\theta_{t}-\theta_{\text {res }}}{\theta_{\text {sat }}-\theta_{\text {res }}}=1-\frac{\ln \left(I_{t} / I_{\text {sat }}\right)}{\ln \left(I_{\text {res }} / I_{\text {sat }}\right)}
$$

where $\theta_{t}\left(\mathrm{~cm}^{3} \mathrm{~cm}^{-3}\right)$ is the point water content matrix representative of the sample (i.e., values for all pixels within the sample), $I_{t}$ is the emergent light intensity at time $t$ in the $x, z$ plane of the soil profile, and $\theta_{\text {sat }}$ and $\theta_{\text {res }}$ are the saturated and residual moisture conditions $\left(\mathrm{cm}^{3} \mathrm{~cm}^{-3}\right)$ of the sample. However, Niemet et al. (2002) later avoided the use of equation 4 due to the consideration of uniform pore size because the pore size distribution is non-uniform as described by the soil water characteristic curve. They suggested a physical model requiring the calibration of a fitting function for $S_{e}(I)$.

\section{RECASTING OF NIEMET AND SELKER (2001) EQUATION}

In this section, we examine a recasting of the original Niemet and Selker (2001) equation (eq. 4) with the improved assumption of a non-uniform pore size distribution and including the changing conditions that the light encounters under variable moisture conditions. Due to the assumption of water films clinging to the interstitial area, there is always an active interphase $(j=1)$ present between water and solid particles throughout the water content range. This assumption 
is based on the fact that once the soil profile is initially wetted, a hygroscopic water film remains clinging to the sand particles even under residual moisture conditions. Residual water content is the point on the soil-water characteristic curve where the soil suction phase changes from being held primarily by capillary action force to being held in the soil primarily by adsorption force (water is present as thin films surrounding the soil particles). Therefore, the effective pore space exists typically between water films instead of between sand particles (Niemet and Selker, 2001). Hence, this assumption implies that the effect of sand-air interphases $(j=3)$ is negligible, and the water-air interphase $(j=2)$ is reduced when the pore is filled with water until it completely disappears in saturated conditions. In addition, the total surface area of the sand-water interphase $(j=1)$ in the media is constant in the presence of water films throughout the soil moisture range considered. Therefore, the interphase between water and solid particles $(j=1)$ is independent of $S_{e}$. Further, in equation 2, instead of a uniform particle diameter, Niemet and Selker (2001) considered the thickness of the solid particles through the media $\left(d_{s}, \mathrm{~cm}\right)$, as in Hoa (1981):

$$
d_{s}=d(1-\phi)
$$

where $d$ is the sample thickness $(\mathrm{cm})$, and $\phi$ is the porosity $\left(\mathrm{cm}^{3} \mathrm{~cm}^{-3}\right)$. Therefore, no assumptions are required about the geometry and diameter of the particles or pores. The general expression (eq. 2) of light intensity transmitted through the porous media can then be simplified as follows:

$$
I_{t}=I_{\text {in }} \tau_{1}^{2 k} \tau_{2}^{2 k\left(1-S_{e}\right)} \cdot e^{\left(-\alpha_{s} d(1-\phi)\right)}
$$

Following Niemet and Selker (2001), two expressions are obtained from equation 6 to express the boundary conditions of light traversing the media under both residual conditions, $I_{\text {res }}\left(S_{e}=0\right)$, and saturated conditions, $I_{\text {sat }}\left(S_{e}=1\right)$ :

$$
\begin{gathered}
I_{\text {res }}=I_{\text {in }} \tau_{1}^{2 k} \tau_{2}^{2 k} \cdot e^{\left(-\alpha_{s} d(1-\phi)\right)} \\
I_{\text {sat }}=I_{\text {in }} \tau_{1}^{2 k} \cdot e^{\left(-\alpha_{s} d(1-\phi)\right)}
\end{gathered}
$$

Dividing equations 6 and 7 by equation 8 yields:

$$
\begin{gathered}
\frac{I_{t}}{I_{\text {sat }}}=\tau_{2}^{2 k\left(1-S_{e}\right)} \\
\frac{I_{\text {res }}}{I_{\text {sat }}}=\tau_{2}^{2 k}
\end{gathered}
$$

Substituting equation 9 into equation 10 and solving for $S_{e}$ yields the original Niemet and Selker (2001) equation (eq. 4) but derived without the initial limiting assumptions.

Finally, the point water content matrix $\left(\theta_{t}\right)$ is obtained from equation 4 , and the total volume of instantaneous water present in the soil profile within the experimental device $\left(V_{t}, \mathrm{~cm}^{3}\right)$ is obtained by numerical integration of the product between the water content in each pixel at time $t\left(\theta_{t}\right)$ and the thickness of the sample $(d, \mathrm{~cm})$ in both dimensions of the $\{x, z\}$ plane occupied by the sample:

$$
V_{t}=d \int_{x=0}^{x} \int_{z=0}^{z} \theta_{t} d z d x
$$

From this expression, the cumulative volume of water drained from the system at each instant $t\left(V_{\text {drain }(t)}, \mathrm{cm}^{3}\right)$ can be obtained:

$$
V_{\text {drain }(t)}=V_{\text {sat }}-V_{t}
$$

The efficiency of the LTM physical model to estimate water content, $\theta(x, z, t)$ (eq. 4), in a sample and the soil profile drainage outflow (eq. 11) can be verified by comparison with reference soil moisture cells and mass balance based on the $V_{\text {drain }(t)}$ observed time series from the experimental device (see the Materials and Methods section).

\section{Physical Identification Of Number of Pores}

Two approaches have been proposed to calculate $k$ needed in equations 2 to 10 . Hoa (1981) first proposed an empirical calibration of the number of water-filled pores ( $p$, related to $k$ by $p=S k$ ) from the water content of the sample $\left(\theta_{t}\right)$ and the measured light intensity $\left(I_{t}\right)$. Tidwell and Glass (1994) calibrated $k$ from water saturation and light intensity experimental data. Using a different approach, Niemet and Selker (2001) proposed an expression to calculate $k$ derived from Tidwell and Glass (1994):

$$
k=\frac{\ln \left(\frac{I_{\text {sat }}}{I_{d r y}}\right)}{2 \ln \left(\frac{\tau_{1}}{\tau_{3}}\right)}
$$

In this article, a direct method is proposed to physically characterize $k$ through a sample of translucent porous media. In addition to the matrices corresponding to $I_{\text {sat }}$ and $I_{\text {res }}$ for all the pixels in the translucent soil profile, a digital image obtained with a water table under steady conditions, $I_{w t}(x, z)$, is also required following the experimental procedure proposed in the following section. Then, by means of numerical analysis of the digital image, the average height from the static water table reached by the capillaries $\left(h_{c f},-\mathrm{cm}\right)$ is extracted. The radius of the capillary (pore), $r(\mathrm{~cm})$, is then calculated from the Jurin law of capillary rise:

$$
r=\frac{2 \sigma \cdot \cos \beta}{\rho g\left|h_{C F}\right|}
$$

where $\sigma$ is the surface tension of the fluid $\left(\sigma_{w}=72.8 \mathrm{~g} \mathrm{~s}^{-2}\right)$, $\beta$ is the contact angle between the fluid and the capillary $\left(^{\circ}\right)$, which Weisbrod et al. (2009) calculated as $\beta=2^{\circ}$ from wet sand columns contained in acrylic cylinders, $\rho$ is the fluid (water) density $\left(\rho_{w}=1 \mathrm{~g} \mathrm{~cm}^{-3}\right), g\left(\mathrm{~cm} \mathrm{~s}^{-2}\right)$ is the gravity acceleration $\left(9.81 \mathrm{~m} \mathrm{~s}^{-2}\right)$, and $h_{c f}$ is the measured capillary rise $(\mathrm{cm})$. Finally, $k$ is obtained from the quotient between the total thickness of pores, which coincides with that of air under completely dry conditions, $d_{a}=\phi d(\mathrm{~cm})$, where $r$ is obtained from equation 14 : 


$$
k=\frac{d_{a}}{r}=\frac{\phi d g\left|h_{C F}\right|}{2 \sigma \cdot \cos \beta} \approx 6.742 \phi d\left|h_{C F}\right|
$$

\section{Materials ANd Methods}

The experimental plan included a static point moisture evaluation and a dynamic drainage experiment. As described below, a complete soil thin-layer laboratory device was used for the point moisture evaluation and modified for the dynamic drainage experiment. The devices are presented below, followed by the experimental plan for each of the two experiments.

\section{EXPERIMENTAL DEVICES}

The LTM was used in the point moisture and drainage experiments (figs. $2 \mathrm{a}$ to $2 \mathrm{c}$ ) to quantify the instantaneous pore-scale water content in porous media from the intensity

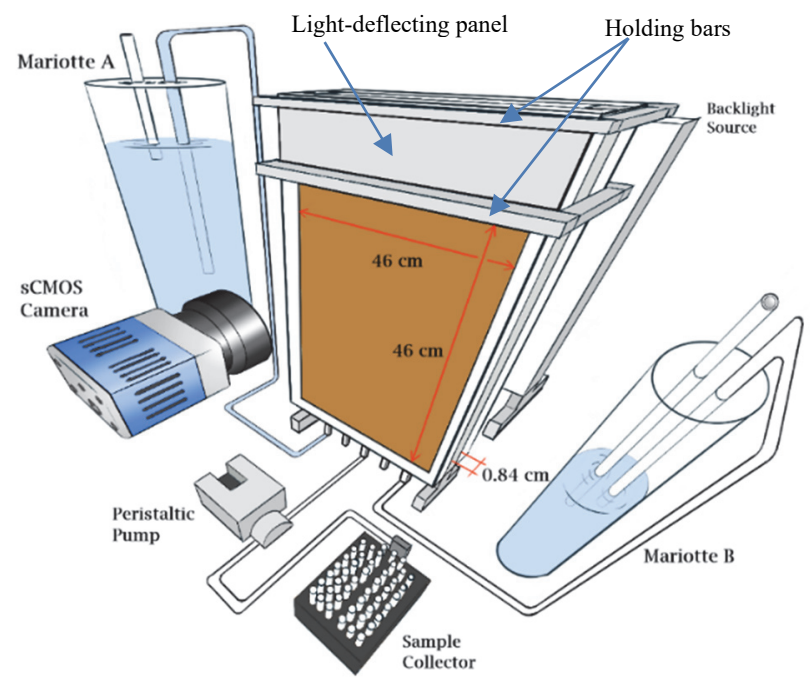

(a)

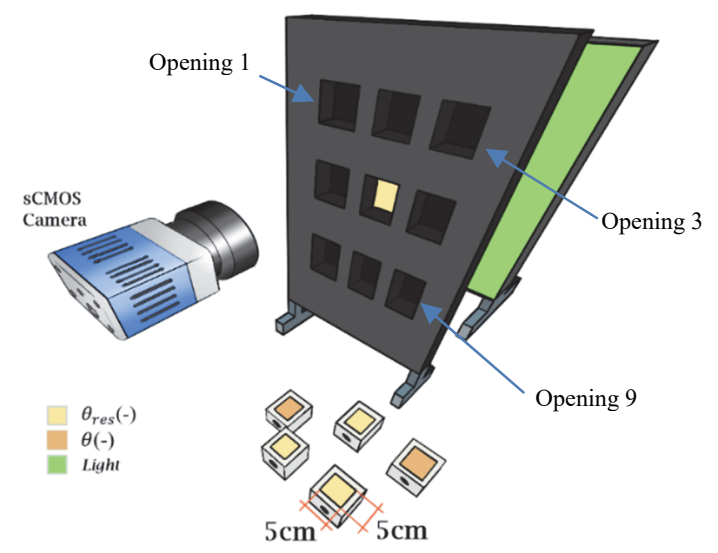

(c) of light transmitted through the media. Using this technique, the attenuation of the light intensity after being transmitted from a light source (LED panel white light, $22 \mathrm{~W}, 60 \mathrm{~Hz}$, Luxrite) to its capture with a digital camera (sCMOS monochrome, pco.edge $4.2,20 \mathrm{~mm}$ focal distance) was determined after its passage through the porous media (figs. 2a to 2c). For use in the experiments, cleaned silica sand (Edgar Minerals) was used as the solid phase and was sieved into three size fractions: fine $(0.10$ to $0.36 \mathrm{~mm})$, medium ( 0.36 to $0.60 \mathrm{~mm}$ ), and coarse (0.60 to $1.00 \mathrm{~mm}$ ).

The experimental device containing the porous media (figs. 2a, 2b, and 2d) consisted of an inner U-shaped aluminum frame (height $=60 \mathrm{~cm}$, width $=50 \mathrm{~cm}$, and width of arms $=2.5 \mathrm{~cm}$ ) with two natural rubber gaskets. This frame, covered with the gaskets, was placed between two scratchresistant polycarbonate panels $(60 \mathrm{~mm} \times 50 \mathrm{~mm} \times 9 \mathrm{~mm}$ each) to form a two-dimensional chamber. To ensure sealing of the chamber and avoid water loss, high-vacuum grease

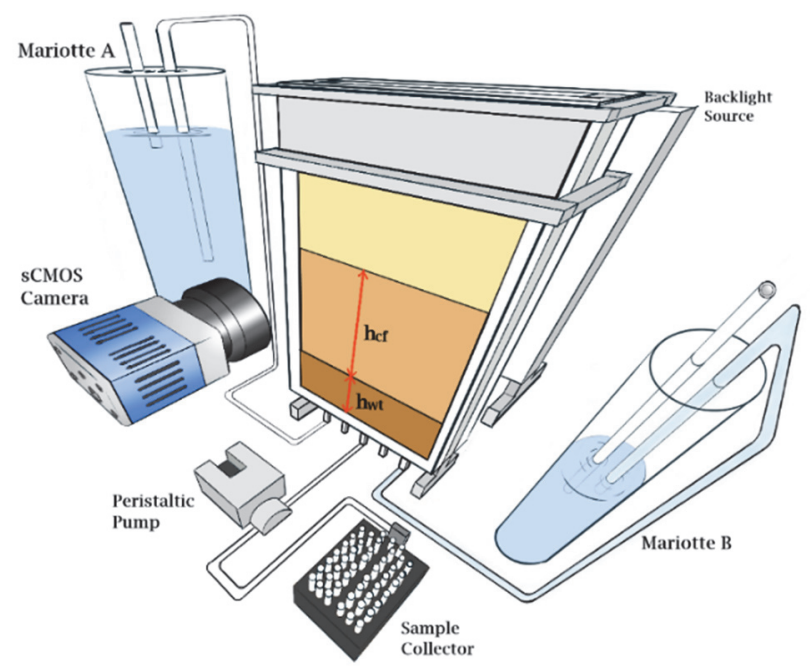

(b)

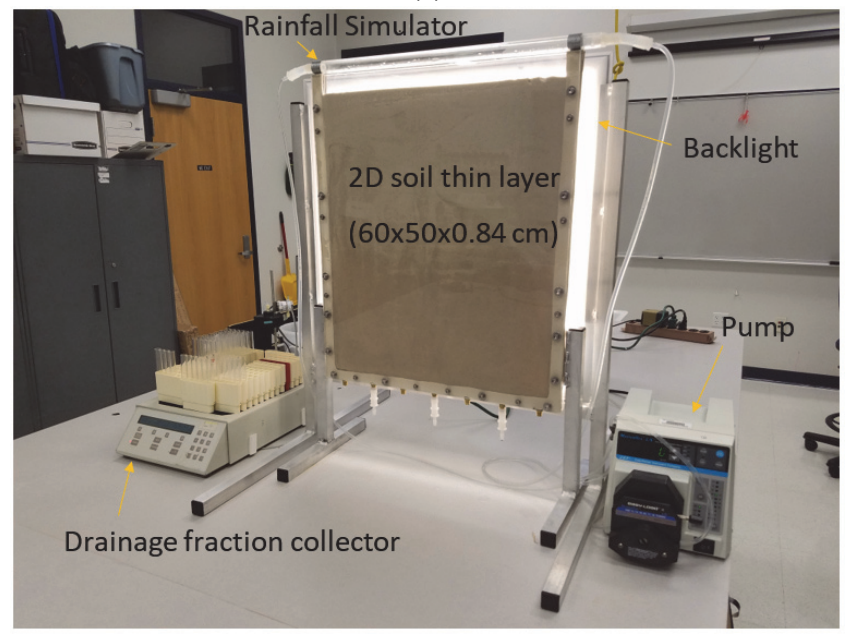

(d)

Figure 2. Experimental device with (a) porous media under saturated moisture conditions $\left(\theta_{\text {sat }}, \mathrm{cm}^{3} \mathbf{c m}^{-3}\right)$ and (b) porous media under hydrostatic equilibrium conditions with a bottom water table, where $h_{w t}$ is the height of the water table measured from the bottom of the device (cm), and $h_{c t}$ is the height due to capillary rise of the sand fraction considered (cm); (c) modification of the device for evaluation of point moisture prediction showing six $25 \mathrm{~cm}^{2}$ cells, where $\theta_{\text {res }}$ is the residual water content in the sample $\left(\mathrm{cm}^{3} \mathbf{c m}^{-3}\right), \theta$ is the variable water content in the sample $\left(\mathrm{cm}^{3} \mathrm{~cm}^{-3}\right)$, and the openings are numbered 1 to 9 following the sequence that can be inferred from the figure; and (d) photo of experimental device. 
(Dow Corning) was used to seal the chamber. Two stainless steel bars were used to hold the top of the chamber and prevent deformation of the polycarbonate panels when the chamber was filled with saturated porous media (fig. 2a). One of the holding bars was located at the upper end of the device, while the other bar was placed at a variable position based on the height of the porous media.

The dimensions of the free space for the porous media inside the chamber were a width of $46 \mathrm{~cm}$, a thickness of $0.84 \mathrm{~cm}$, and a variable height of less than $46 \mathrm{~cm}$. To ensure homogeneous packing of the sand, a mechanical laboratory sieve (Octagon 200) was modified so that it could slowly fill sand into the chamber while vibrating. For this purpose, a high-density polyethylene (HDPE) pan was installed on the body of the mechanical sieve shaker to hold the device on top.

The front and rear top spaces between the two holding bars were covered with two light-deflecting aluminum panels to prevent entry of external light from above the sand surface. The device also included five inlet/outlet ball valves at its base, separated from the porous media by an aluminum mesh $(2.8 \mu \mathrm{m})$ to prevent sand loss. Finally, an external aluminum frame was used to allow the device to stand upright while the camera remained fixed at a distance of $1 \mathrm{~m}$ from the device, centered on the $46 \mathrm{~cm} \times 46 \mathrm{~cm}$ plane, and the LED light panel was placed at a distance $f=13 \mathrm{~cm}$ behind the device. This distance was determined by moving the light panel away from the device, which was filled with saturated coarse sand, until no light saturation was achieved in the sCMOS camera. A large dark chamber $(60 \mathrm{~cm} \times 50 \mathrm{~cm} \times$ $110 \mathrm{~cm}$ ) made of black cardboard covered the device during the measurements to avoid external light artifacts in the images. For the drainage experiments, the experimental device (fig. 2b) was equipped with two Mariotte-type siphons (A and B), a peristaltic pump (Cole Palmer Masterflex), and a sequential sample collector (Spectra/Chrom CF-1, unit tube volume $=10 \mathrm{~mL}$ ).

The original device was modified to evaluate the efficiency of the point water content predictions (fig. 2c). A plywood panel with a black painted exterior was fabricated with the same dimensions as the chamber $(60 \mathrm{~cm} \times 50 \mathrm{~cm})$. The panel contained nine square openings of $25 \mathrm{~cm}^{2}$ size, regularly distributed in a $3 \times 3$ matrix. Six transparent square cells of $25 \mathrm{~cm}^{2}$ size were constructed so that they could be placed in any of the nine openings of the verification device. These cells had the same material characteristics and thickness as the experimental device (fig. 2c). Each cell had an inner frame closed on all four sides with two holes that served as water entry or exit points: one on the top (i.e., open to the surface) and the other on the bottom (i.e., with aluminum mesh of $2.8 \mu \mathrm{m}$ to avoid sand loss). The cells allowed varying the porous material (fine, medium, and coarse sand) and $\theta$ (when filled with different water volumes) and later obtaining the estimated $\theta$ after post-processing the digital images using MATLAB (Verification_Device.m in the Supplemental Material (available at https://doi.org/10.13031/ 14442632.v1)). The cell positions relative to the center of the chamber allowed us to investigate the effect of measuring $I$ through different camera angles in the plane.

\section{Experimental Procedure \\ Validation of LTM Point Soil Water Content}

Each size fraction of the sand was first washed with water until the turbidity of the washing solution completely disappeared and then dried at $45^{\circ} \mathrm{C}$ for two days to prevent coloration of the particles (Niemet and Selker, 2001; Bob et al., 2008). The dried sand was stored in separate watertight containers as fine, medium, and coarse porous media for later use.

The six cells of the verification device (fig. 2c) were disconnected from each other and filled with the different dry media (fine, medium, and coarse sand) for each experiment. Two cells with each sand type were tested. Each cell was weighed when it was still empty. To achieve a bulk density similar to that achieved in the full experimental device, a funnel was inserted into the upper hole to slowly fill each cell while the cell was located on the vibrator pan. Each cell was weighed again when it was filled with the dry porous media. Finally, the cells were immersed in water without the water reaching the top of the cells. Thus, the water was raised by capillary action from the lower entrance of the cell, to allow expelling of air through the top of the soil. The cells were left to stand for $24 \mathrm{~h}$ to remove entrapped air.

The first moisture stage of the sample was performed when all the cells were saturated with water by topping each cell with water. Each cell was then sealed and weighed, placed in the verification device, and the transmitted light intensity was measured with the sCMOS camera. To do this, the first cell was placed in the center opening of the device, as this was assumed to be the position most susceptible to light saturation. To avoid the influence of light from outside the experiment, all openings that were not being used were covered. The exposure time (ms) of the camera was adjusted so that the saturated water content could be clearly measured without producing light saturation in the image. In this way, increasing exposure times were obtained for the coarse $(22 \mathrm{~ms})$, medium $(70 \mathrm{~ms})$, and fine $(150 \mathrm{~ms})$ sand fractions. After measuring the light intensity for all samples in the center position, the light intensities in the other openings of the verification device were measured by moving the cells around the device and covering the unused openings.

To predict the water content in the intermediate moisture stages, the water contents at $\theta_{\text {sat }}$ and $\theta_{\text {res }}$ obtained during the tests with the experimental device were used, and three intermediate points were calculated between them $(25 \%, 50 \%$, and $75 \%$ of $\theta_{\text {sat }}$ ). The procedure was performed by draining the cells from full saturation to achieve conditions similar to those obtained in the follow-up drainage experiment. Decreasing moisture values in the cells were obtained by applying suction slowly with the peristaltic pump at the bottom outlet of the cell, while the cell was placed horizontally to reduce the effect of gravity. This procedure was performed until an average water content was obtained in the cell for each saturation stage. When the weight of the cell reached the estimate for the corresponding target moisture, the measured weight was recorded, and the light intensity was measured for each cell $(27,778$ pixels $)$ in all openings of the verification device. This process was repeated for each cell, opening, water content, and soil texture. Finally, the cell- 
measured (observed) and LTM-predicted $\theta$ values (eq. 4) were compared to evaluate the efficiency of the LTM to model point soil moisture in the cells and soil profile.

\section{Soil Drainage Flow and Number of Pores}

After the full device was prepared, three images were required to set the boundary conditions and calculate the number of pores: (1) media under conditions of complete water saturation (i.e., $I_{\text {sat }}$ matrix after image post-processing), (2) residual saturation $\left(I_{r e s}\right)$, and (3) media under initial residual conditions when a stationary water table was established at the base of the plane $\left(I_{w t}\right)$. In addition, the values of $\theta_{\text {sat }}$ and $\theta_{\text {res }}$ were obtained from the internal volume of the device and the volume of water required to saturate the media. The water content was used in the subsequent calculation of the point soil moisture matrices $\left(\theta_{t}\right)$ from all pixels $(4,194,304$ pixels $)$ in the chamber at time $t$. From the camera resolution and the surface measurements of the chamber, the dimensions $d x$ and $d z(0.03 \mathrm{~cm} \times 0.03 \mathrm{~cm})$ of each pixel in the $x, z$ plane were calculated. The total instantaneous volume of water in the system $\left(V_{t}\right)$ and the volume drained $\left(V_{\operatorname{drain}(t)}\right)$ were calculated at each time step.

The experiment was initiated by saturating the sand with water from below using the Mariotte A siphon connected to valve 1 (fig. 2a). Once the media were saturated all the way to the top of the chamber, the volume of water required $\left(V_{\text {sat }}\right)$ was recorded, and a corresponding image at full saturation was captured to calculate $I_{s a t}$. Subsequently, valve 1 was closed, and the peristaltic pump connected to valve 3 was activated to drain the media at a constant flow rate of $5.6 \mathrm{~mL} \mathrm{~min}{ }^{-1}$. This low drainage rate was selected to approximate hydrostatic conditions at each $t$ (Niemet and Selker, 2001). While progressively draining the sand fraction, images were taken (with corresponding $I_{t}$ ) at an interval of $1 \mathrm{~s}$ between images. The drainage water was collected with the sequential fraction sampler at a rate of 1 tube $\mathrm{min}^{-1}$. The sequence of images captured during draining was recorded for later verification of the model, together with the values measured in the sample collector. This allowed us to compare the outflows observed in the sample collector with the outflows estimated from the sequence of images. To complete the draining process, the sand was allowed to reach residual moisture conditions, at which time another image was taken (with point matrix $I_{\text {res }}$ ) (fig. $2 b$ ), and the total volume of water remaining in the sand at residual moisture conditions was determined from the total volume of water drained off $\left(V_{\operatorname{drain}(t)}\right)$. Finally, using the Mariotte B siphon connected to valve 5 (with the rest of the valves closed), the stationary water table $\left(h_{w t}\right)$ was established for the next 20 to $24 \mathrm{~h}$ at approximately $1 \mathrm{~cm}$ above the bottom of the experimental device, after which an image was captured to obtain $I_{w t}$ (fig. 2b). During this process, the top of the experimental device was covered with plastic film to avoid evaporation losses.

The $I_{\text {sat }}, I_{r e s}$, and $I_{w t}$ point moisture matrices and the entire $I_{t}$ drainage sequence were obtained from post-processed digital images (LTM.m in the Supplemental Material). The point values of the images were transformed from the original 16 bits with a range of values [0-65535] to values within the range [0-1].
From $I_{w t}$, the pore radius and the number of pores traversing the sample thickness could be obtained (eqs. 14 and 15) (Number_of_Pores.m in the Supplemental Material). To calculate $k$, the pore radius $(r)$ representative of the mean sand fraction was obtained from equation 14. Finally, $k$ was calculated according to the method proposed in this study (eq. 5). The $S_{e}$ point matrix was obtained (eq. 4) for the sequence of standardized light intensity matrices $\left(I_{t}\right)$ obtained during draining of the experimental device. Finally, the instantaneous water content $(\theta)$ for each point in the $x, z$ plane of the matrix was obtained from $S_{e}, \theta_{\text {sat }}$, and $\theta_{\text {res }}$.

In addition, this approach identified the width $(d z, \mathrm{~cm})$ and height $(d x, \mathrm{~cm})$ of each pixel from the total physical measurements of the $\{x, z\}$ plane of the sample and the dimensions of the matrix. The volume contained in the system $\left(V_{t}\right)$ for each instant of the time sequence was determined from $d x, d z, d$, and $\theta$ (eq. 11). Finally, the time series of cumulative drained volumes $\left(V_{\text {drain }(t)}\right)$ were obtained from $V_{t}$ and $V_{\text {sat }}$ (eq. 12). From the simulated $V_{\operatorname{drain}(t)}$ sequence and the values measured in the sample collector, the efficiency of the experimental method to calculate water content was examined.

The Nash-Sutcliffe (1970) efficiency coefficient (NSE) was used to test the goodness-of-fit of the LTM, with statistical hypothesis testing for model adequacy (Ritter and Muñoz-Carpena, 2013) that allowed us to identify the significance (p-value) of the model performance exceeding a desirable minimum efficiency threshold (NSE $\geq 0.65$ ). The average prediction error (in units of the output) was measured by the root mean square error (RMSE), defined as the standard deviation of the residuals, and by the normalized root mean square error (nRMSE), defined as the quotient between the RMSE and the total range of the observed values.

\section{RESULTS AND DISCUSSION EXPERIMENTAL VALIDATION OF LTM PoInt SoIl Water CONTENT}

Table 2 shows the results of the characterization of the different types of sand $\left(\theta_{\text {sat }}, \theta_{\text {res }}\right.$, and $\left.h_{c f}\right)$ obtained during the experimental procedure described in the preceding section. While previous authors (Tidwell and Glass, 1994; Niemet and Selker, 2001) tested the water content inside the chamber indirectly from the mass balance at the drainage outflow in the experimental device, our experimental procedure allows a direct and efficient estimation of the soil water content in the profile needed to verify the $S_{e}$ prediction.

Table 2. Values obtained from characterization of fine, medium, and coarse sand during tests with experimental device $\left(\theta_{\text {sat }}=\right.$ saturated moisture content, $\theta_{\text {res }}=$ residual moisture content, $h_{c f}=$ characteristic capillarity rise of the media, $r=$ average pore radius, and $k=$ number of pores through the sample).

\begin{tabular}{cccc}
\hline Parameter & Fine & Medium & Coarse \\
\hline Size $(\mathrm{mm})$ & 0.10 to 0.36 & 0.36 to 0.60 & 0.60 to 1.0 \\
$\theta_{s}\left(\mathrm{~cm}^{3} \mathrm{~cm}^{-3}\right)$ & 0.45 & 0.43 & 0.42 \\
$\theta_{r}\left(\mathrm{~cm}^{3} \mathrm{~cm}^{-3}\right)$ & 0.22 & 0.14 & 0.08 \\
$h_{c f}(-\mathrm{cm})$ & -25.94 & -18.06 & -8.35 \\
$r(\mathrm{~cm})$ & 0.0057 & 0.0082 & 0.0178 \\
$k($ eq. 15) & 12 & 21 & 28 \\
$k$ (eq. 13 and & 15 & 39 & 17 \\
Niemet and Selker, 2001) & & & \\
\hline
\end{tabular}


Preliminary observations obtained by applying the verification device (fig. 3) suggested the existence of two different approximately linear trends between the water content and the emergent light intensity in the sand profile above and below the residual moisture content. Although preliminary, we observed the existence of a smaller slope in light intensity from dry to residual conditions compared to the slope from residual to saturated conditions. This corroborates the Niemet and Selker (2001) approach of developing separate equations for both conditions. Figure 3 highlights the need to normalize the point light intensity values due to the influence of the angle from the camera to a point in the plane of the 2D soil chamber. Figure 3 presents measurements of emergent light intensities without normalization. There was a slight influence due to the angle between the camera and the measured point, which was observed in the approximately parallel lines (i.e., each line corresponds to one cell of the verification device). This angle was zero for the center opening of the verification device (fig. 2c). However, the four openings horizontally and vertically adjacent to the center opening (fig. 2c, openings 2, 4, 6, and 8) were angled with the camera. The openings at the corners had the greatest angles with the camera (fig. 2c, openings 1, 3, 7, and 9). This effect of variable light intensity due to the angle between the camera and each point disappears when the point light intensity values are normalized (eq. 4), stressing the critical importance of normalization.

Figure 4 shows a comparison between the observed and predicted values (eq. 4) of point water content in the cells after being measured at the nine openings of the verification device under the six different stages of saturation for the three soil textures $(n=162)$. The testing efficiency obtained between the point water content measurements and predictions in the six cells resulted in NSE of $0.991\left(\mathrm{p}<10^{-5}\right)$. The corresponding RMSE was $0.008 \mathrm{~cm}^{3} \mathrm{~cm}^{-3}(\mathrm{nRMSE}=2.3 \%)$.

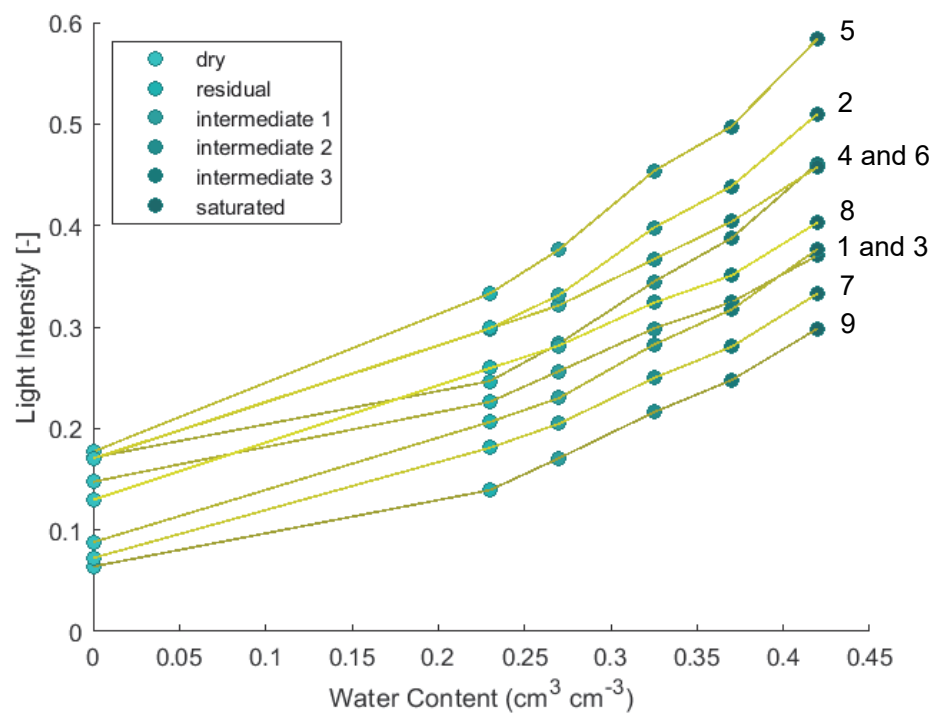

Figure 3. Water content and light intensities measured with fine sand cells in the nine openings of the verification device. Each line represents the light intensity in one of the nine openings of the device. The upper line (1) corresponds to the intensity values obtained in the center opening. The four lines below the center opening ( 2 to 5 ) correspond to the openings located horizontally and vertically adjacent to the center opening. The four lines at the bottom (6 to 9) correspond to the openings at the corners of the verification device.

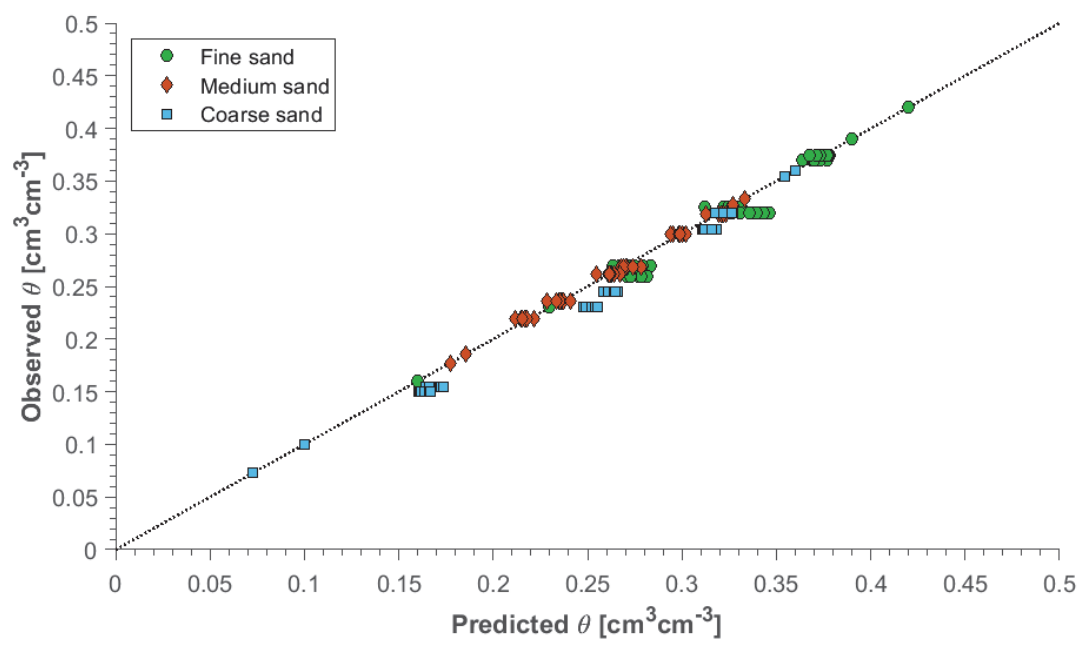

Figure 4. Simulated versus measured water content obtained using $25 \mathrm{~cm}^{2}$ cells in the verification device. Data were obtained with two cells of coarse sand $(0.6$ to $1.0 \mathrm{~cm})$, two cells of medium sand $(0.355$ to $0.6 \mathrm{~mm})$, and two cells of fine sand $(0.1$ to $0.355 \mathrm{~mm})$. 


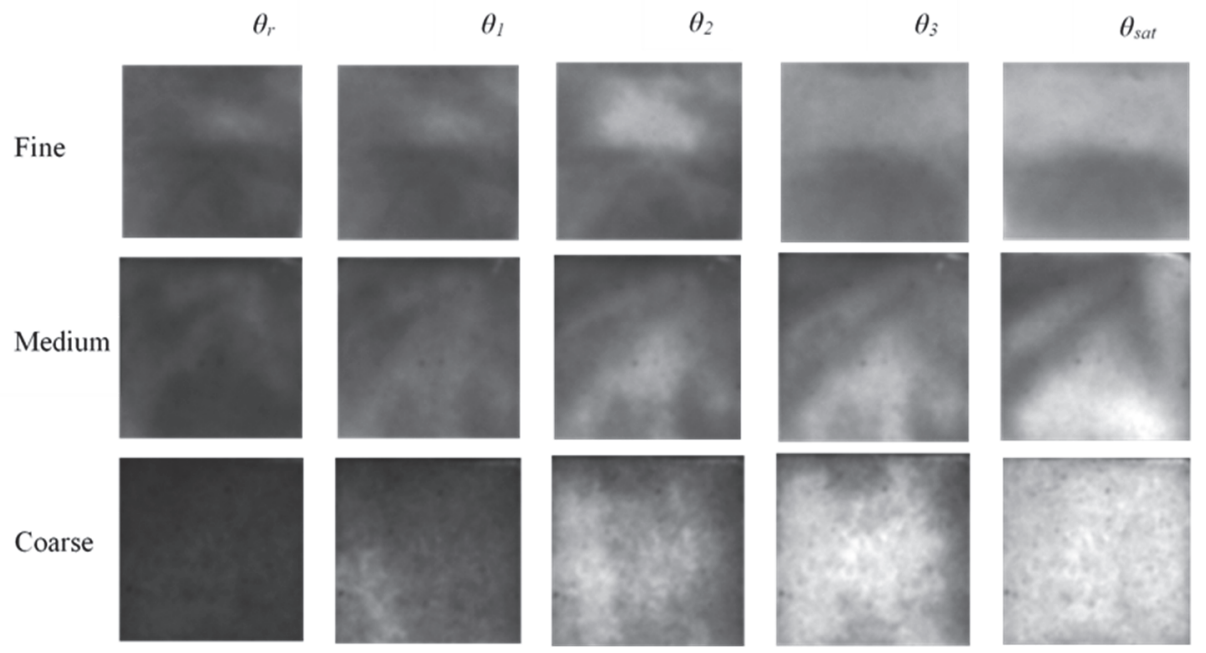

Figure 5. Sample input from the $25 \mathrm{~cm}^{2}$ cells required in Verification_Cells.m in the Supplemental Material. Each row shows a type of sand (fine, medium, and coarse). The columns show the five soil moisture conditions at which each cell was measured, including residual saturation $\left(\theta_{\text {res, }} \mathrm{cm}^{3}\right.$ $\left.\mathbf{c m}^{-3}\right)$, three intermediate water contents $\left(\theta_{1}, \theta_{2}\right.$, and $\left.\theta_{3}, \mathbf{c m}^{3} \mathbf{c m}^{-3}\right)$, and complete saturation $\left(\theta_{\text {sat }} \mathbf{c m}^{3} \mathbf{c m}^{-3}\right)$. The images show the monochromatic emergent light transmitted through the verification cells [0-1].

Predictions of intermediate water content values in cells containing coarse sand were slightly overestimated compared to the measured values (fig. 4) (NSE $=0.986, \mathrm{p}<10^{-5}$, RMSE $=0.012 \mathrm{~cm}^{3} \mathrm{~cm}^{-3}, \mathrm{nRMSE}=4.3 \%$ ), producing a slight deviation from perfect agreement (1:1 line). An increase in the overestimation of the sample moisture was observed for the driest samples. The medium size sand had the best prediction efficiency (NSE $=0.997, \mathrm{p}<10^{-5}, \mathrm{RMSE}=0.003 \mathrm{~cm}^{3} \mathrm{~cm}^{-3}$, nRMSE $=2 \%$ ). Finally, the predictions obtained in the cells containing fine sand were more disparate. While one of the cells obtained a prediction very close to the observed values $\left(\mathrm{NSE}=0.997, \mathrm{p}<10^{-5}, \mathrm{RMSE}=0.004 \mathrm{~cm}^{3} \mathrm{~cm}^{-3}, \mathrm{nRMSE}=\right.$ $2.1 \%$ ), in the other cell the prediction at the two intermediate points closest to residual conditions was overestimated (NSE $=0.975, \mathrm{p}<10^{-5}, \mathrm{RMSE}=0.014 \mathrm{~cm}^{3} \mathrm{~cm}^{-3}, \mathrm{nRMSE}=7.3 \%$ ). This result suggests the possibility of a small experimental error in the measurements of the second cell. However, the overall prediction efficiency was still high (NSE $=0.983$, $\left.\mathrm{p}<10^{-5}, \mathrm{RMSE}=0.01 \mathrm{~cm}^{3} \mathrm{~cm}^{-3}, \mathrm{nRMSE}=5.3 \%\right)$ compared to other experimental methods (Muñoz-Carpena et al., 2005). The strength of equation 4 in determining point water content in the soil profile was clearly supported by the novel cellbased verification procedure proposed in this study.

The source codes programmed in MATLAB and used in this study can be found in the Supplemental Material. A sample input used in the verification methodology for each type of sand under five different soil moisture conditions is shown in figure 5 for the outputs shown in figure 4 . Figure 5 shows the monochromatic emergent light using the three sand fractions and five different water contents as captured by the sCMOS camera and processed in MATLAB.

\section{EXPERIMENTAL VALIDATION OF LTM SOIL \\ Drainage Flow and Number of Pores}

Figure 6 shows color images corresponding to the steady water table $\left(I_{w t}\right)$. The characteristic capillary rise of the media is identified in the $\{x, z\}$ plane (black line) in each graph, from which the average capillary ascent $\left(h_{c f}\right)$ of each type of sand was determined (table 2). The representative $r$ values calculated from $h_{c f}$ (eq. 14) and the $k$ values (eq. 15) are also shown in table 2. A homogeneous pore size would result in the same soil moisture and hence uniform light intensity throughout the capillary rise. However, as expected, under hydrostatic conditions, we observed a decreasing outgoing light intensity corresponding to decreasing water content with increasing distance from the water table.

Following the reasoning of Niemet and Selker (2001) to obtain equation 15 , and taking into account the change from dry to residual conditions from Tidwell and Glass (1994), it is feasible to derive an expression to calculate $k$ for their models. Therefore, the only change with respect to equation 13 was the use of the point light intensity under residual conditions instead of dry conditions. This result suggested that $k$ is a fitting parameter with no direct physical meaning. Thus, we compared the results obtained by applying equation 13 to calculate $k$ with the values obtained from its physical characterization using equation 15 mentioned above (table 2). The results from equation 13 and the modified equation to represent the boundary conditions of Niemet and Selker (2001) returned different values (table 2), and both were different from those obtained in the characterization of $k$. These results indicate that the sand sample $k$ value has no direct physical meaning, being only a fitting parameter in the semi-empirical modeling frameworks. The normalization of the Niemet and Selker (2001) physically based model does not rely on fitting parameters, overcoming the previous semi-empirical modeling frameworks, but it requires baseline measurements for the saturated and residual contents.

Finally, following the drainage experiment described above, the point $S_{e}$ matrices were obtained for each sand type under dynamic soil water conditions. For each time step during the drainage experiment, the point water content matrices $\left(\theta_{t}\right)$ were determined for each sand profile (eq. 4) from the values obtained in the characterization of each sand type (table 2). The cumulative water drained in a particular instant 


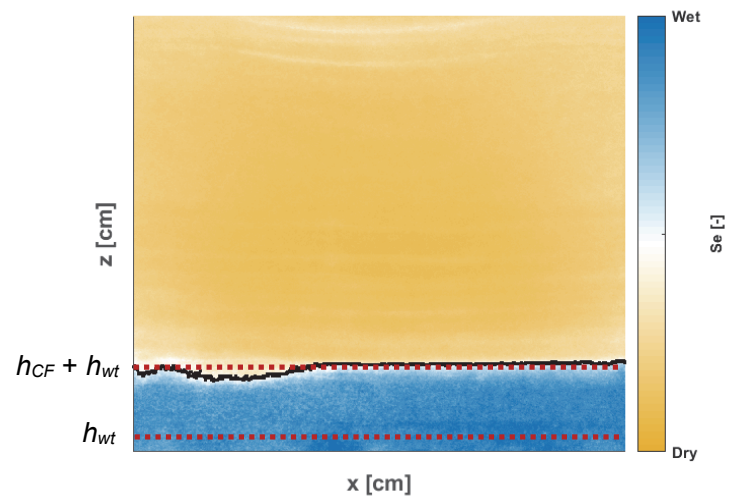

(a)

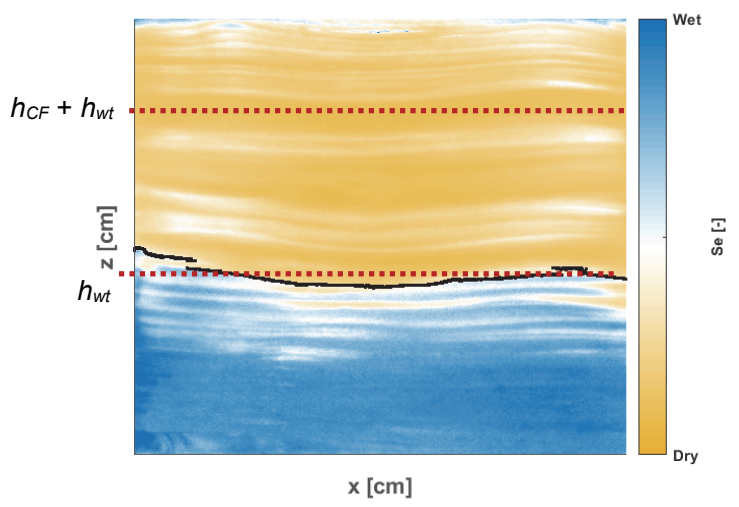

(b)

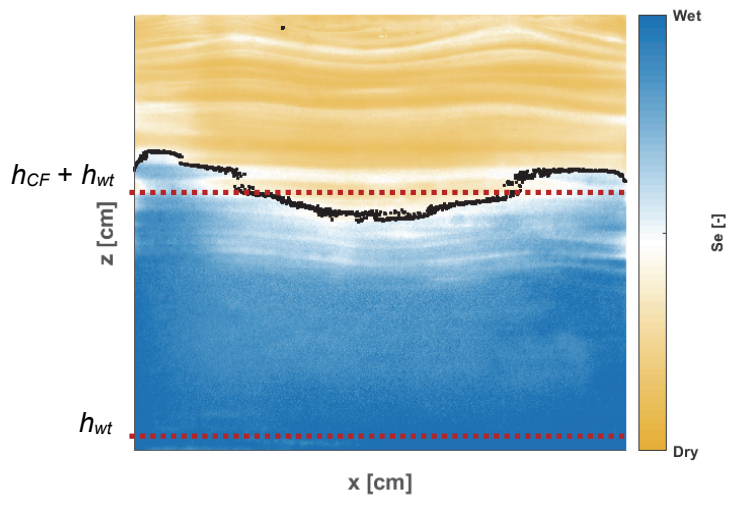

(c)

Figure 6. Graphic representation of standardized point matrices obtained during calculation of the capillary rise (black line) of each sand type. Dashed red lines represent the water table height $\left(h_{w}, \mathrm{~cm}\right)$ and the capillary height $\left(h_{c},-\mathrm{cm}\right)$ measured from it. Data were obtained with: (a) coarse sand $\left(0.6\right.$ to $1.0 \mathrm{~cm}, h_{c f}=\mathbf{- 8 . 3 5} \pm 0.47 \mathrm{~cm}$ ), (b) medium sand ( 0.355 to $\left.0.6 \mathrm{~mm}, h_{c f}=-18.06 \pm 1.06 \mathrm{~cm}\right)$, and (c) fine sand (0.1 to $\left.0.355 \mathrm{~mm}, h_{c f}=-25.94 \pm 2.12 \mathrm{~cm}\right)$.

(fig. 7) was then obtained from the initial measurement of the saturated water volume $\left(V_{\text {sat }}\right)$ and equations 11 and 12 .

Figure 7 shows the measured and predicted water drainage outflow for the three soil textures. For coarse sand (fig. 7a), the observed trend was close to that predicted with equation 4, although there was an increasing deviation in time as the soil drained. When the drainage experiment in coarse sand concluded, the moisture conditions were far from residual. However, it was expected that equation 4 would have autocorrected the prediction trend toward the measured values when approaching residual conditions to follow a non-linear trend similar to that measured in the cells. This decrease in efficiency as we approached residual content was also observed by Niemet and Selker (2001) and Bob et al. (2018). The measured and predicted cumulative drainage volumes for medium sand (fig. 7b) agreed closely, showing the expected non-linear change as the water content in the chamber approached residual conditions, with small deviation from the observations. Finally, the predicted values for fine sand (fig. 7c) deviated slightly from the observations during the first $5 \mathrm{~min}$ of the experiment but closely matched the last part of the experiment. This result coincides with that observed in one of the fine sand verification cells described above.

Despite the small deviations from the observations, the prediction efficiency was excellent (table 3 ) and in all cases passed the statistical significance test for an acceptable model (NSE $\geq 0.65$ ) with a p-value of $\sim 0$ and a very good model "pedigree" (Ritter and Muñoz-Carpena, 2013), demonstrating the strength of the recast Niemet and Selker (2001) equation and the proposed experimental method to obtain reliable pore-scale point water content in translucent media, particularly in medium and fine sand.

\section{Conclusions}

This study demonstrated the application of the light transmission method (LTM) to predict soil moisture at pore scale and high spatial and temporal resolutions from the intensity of light transmitted through a translucent soil profile. To overcome some of the initial limitations of existing methods, the original Niemet and Selker (2001) equation was recast. A novel cell-based verification method was proposed to test the efficiency of the method as well as the Niemet and Selker (2001) equation to predict pore-cluster scale point water contents in the soil profile, with excellent results. An experiment based on the Jurin capillary rise equation was also proposed to determine: (1) the representative pore radius $(r)$ of any translucent soil profile, and (2) the average number of pores through the soil profile. The physical characterization of this parameter completed the efforts of previous authors to physically parameterize the combined Beer-Lambert and Fresnel equations. However, it was also shown that the parameter for the number of pores through a soil sample $(k)$ is semi-empirical (not directly identifiable) and therefore can be considered a fitting parameter in the combined Beer-Lambert and Fresnel equation models derived from it.

Several limitations were identified in this study. While the LTM was successfully applied to coarse, medium, and fine sand particles, the fine sand used in this study needed long exposure to the light $(150 \mathrm{~ms})$, which could limit the ability of the LTM with finer media than those used in this study. Even with careful packing, heterogeneities are more frequent as the particle size distribution decreases due to local differences in particle sizes and densities, limiting the efficiency of LTM with finer media. During the mass balance drainage experiment, it was observed that the performance of the Niemet and Selker (2001) equation generally decreased slightly as the media approached residual conditions, 

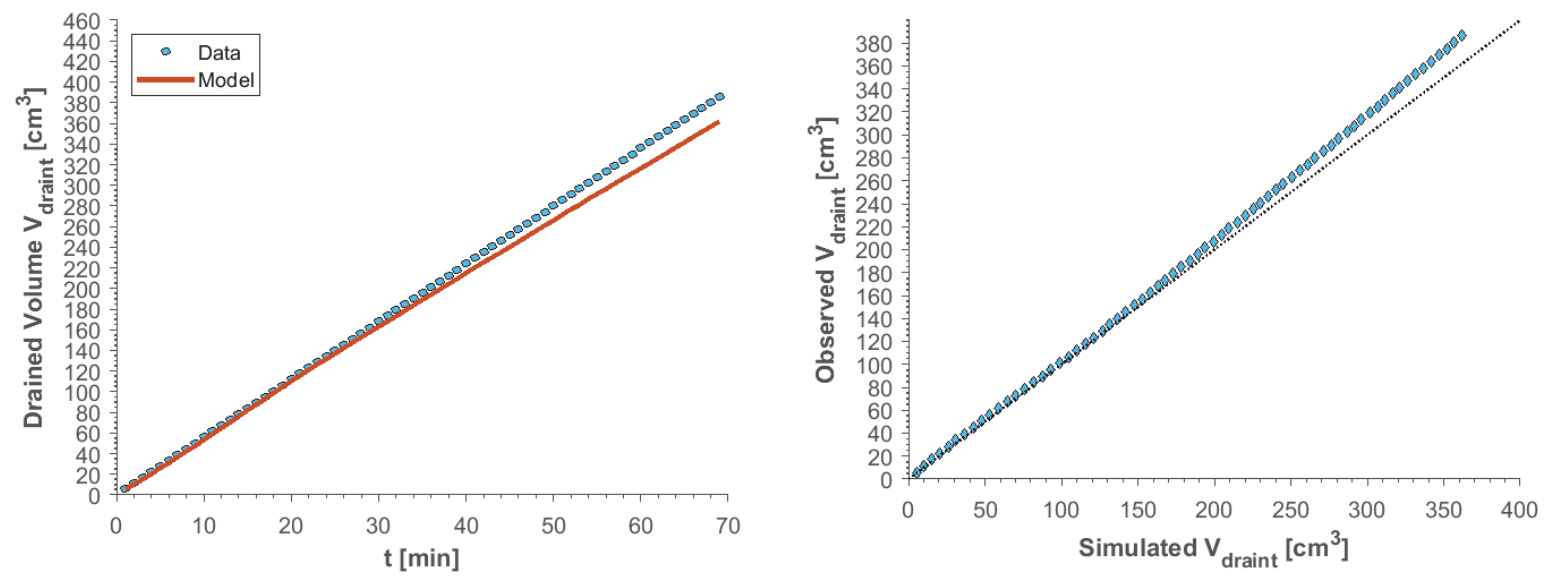

(a)
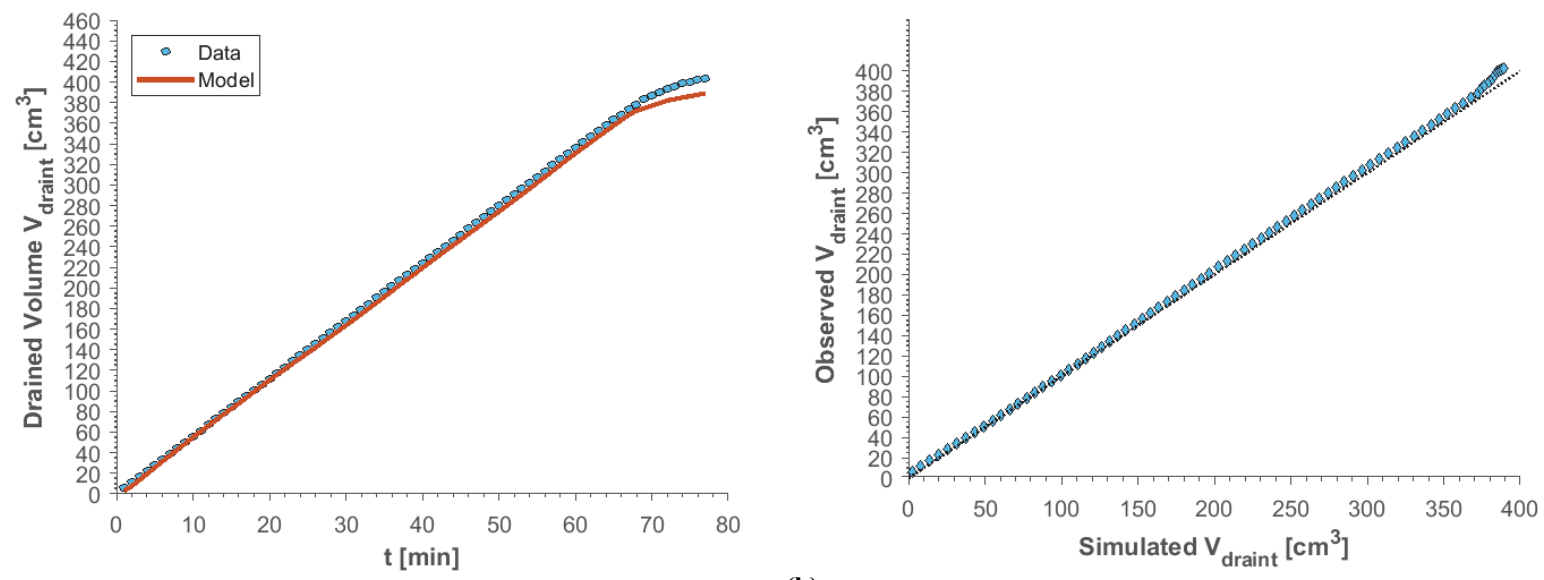

(b)
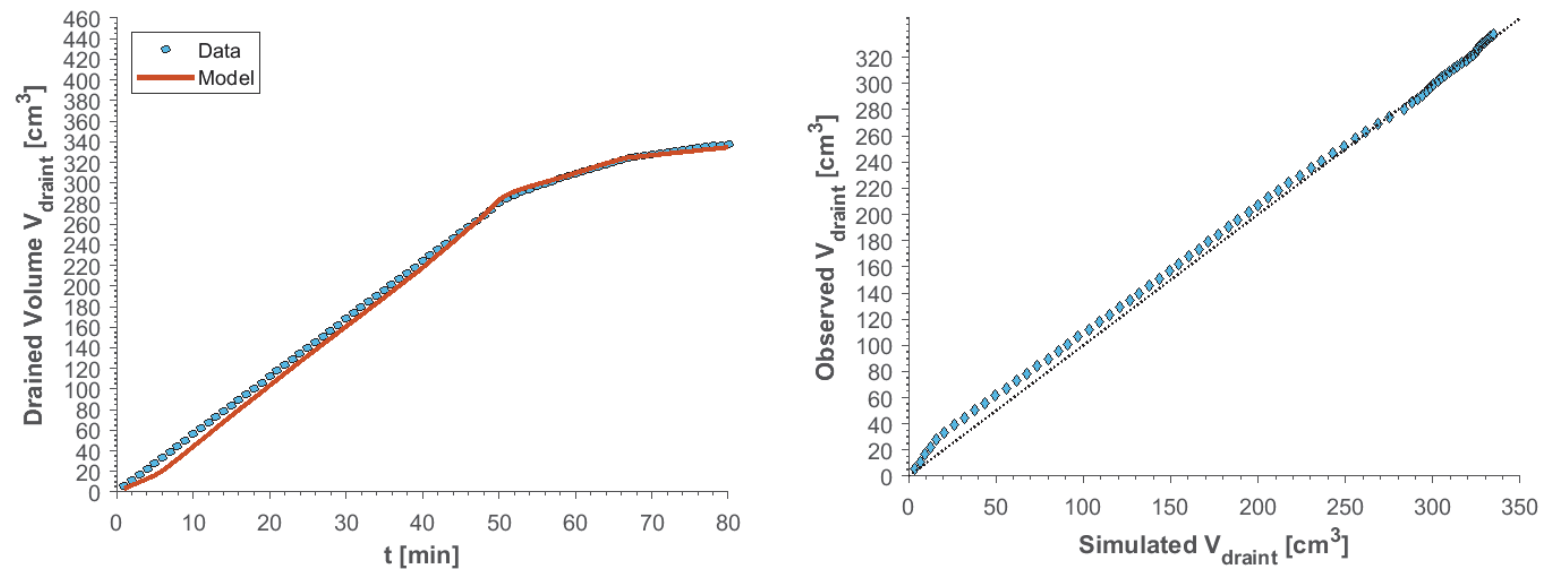

(c)

Figure 7. Observed and predicted drainage values for (a) coarse sand (0.6 to $1.0 \mathrm{~mm})$, (b) medium sand (0.355 to $0.6 \mathrm{~mm})$, and (c) fine sand (0.1 to $0.355 \mathrm{~mm})$. Left column shows cumulative drained volume time series $\left(V_{\text {drain }}(t), \mathrm{cm}^{3}\right)$ simulated and obtained with experimental device during drainage experiments. Right column shows observed versus simulated instantaneous drained volume resulting from drainage experiments.

while deviation occurred closer to saturated conditions with the fine sand. Future research should focus on the observation and integration of preferential flow and transport processes, which are present in riparian vadose zones and are described in dual-permeability modeling frameworks, such as longitudinal flow and transport, lateral mass transfer, matrix flow, and the presence of seasonal shallow water tables.

This study verified the efficiency of the Niemet and Selker (2001) model to obtain soil moisture from transmitted light at laboratory scale, which will allow the determination of flow processes that require very high resolutions that common dielectric methods do not currently achieve. For example, the high spatiotemporal resolution of the LTM offers the opportunity to observe lateral mass transfer from the macropore to the soil matrix during flow. It will also support study of the potential effects of transient rapid preferential flow in important applications such as runoff pollution mitigation in riparian buffers. The experimental plan developed 
Table 3. Measured and predicted drainage experiment results for the Niemet and Selker (2001) model showing goodness-of-fit between simulated and measured values of the time series of water drained from the system $\left(V_{\operatorname{drain}(t)}, \mathbf{c m}^{3}\right)$ for the three sand fractions considered: $\mathbf{R}^{2}=$ Pearson coefficient of determination, $\mathrm{NSE}=$ Nash-Sutcliffe coefficient of efficiency, and RMSE = root mean square error $\left(\mathrm{cm}^{3}\right)$. The p-values for NSE correspond to the significance test for an unacceptable model (NSE $\leq$ 0.65) (Ritter and Muñoz-Carpena, 2013).

\begin{tabular}{cccc}
\hline Sand Fraction & $\mathrm{R}^{2}$ & NSE & RMSE \\
\hline Fine & 0.9997 & $0.9971\left(\mathrm{p}<10^{-5}\right)$ & $5.70 \mathrm{~cm}^{3}$ \\
Medium & 0.9999 & $0.9988\left(\mathrm{p}<10^{-5}\right)$ & $4.18 \mathrm{~cm}^{3}$ \\
Coarse & 0.9998 & $0.9889\left(\mathrm{p}<10^{-5}\right)$ & $11.77 \mathrm{~cm}^{3}$ \\
\hline
\end{tabular}

in this study will allow integration of non-linear and nonsequential preferential flows under riparian conditions, with the presence of a typical seasonal shallow water table. This will lead to new understanding of the complexities inherent in preferential flow in soils and other porous media that are often ignored in current practical applications.

\section{ACKNOWLEDGEMENTS}

This work was partially supported by the USDA-NIFA Grant No. 2016-67019-26855 and Hatch projects 1024705 and 1024706, and the Department of Agricultural and Biological Engineering at the University of Florida. We thank Dr. Christophe Darnault for the initial discussions on the method and equipment, Alvin Langford for all the support in fabricating the experimental device used in this study, and the reviewers of the manuscript for their suggestions and improvements.

\section{SUPPLEMENTAL MATERIAL}

The source codes programmed in MATLAB and used in this work can be downloaded at https://doi.org/10.13031/ 14442632.v1.

\section{REFERENCES}

Alazaiza, M. Y., Ngien, S. K., Ishak, W. M. F., \& Kamaruddin, S. A. (2016). A review of light reflection and transmission methods in monitoring non-aqueous phase liquid migration in porous media. J. Eng. Appl. Sci., 11(4), 2319-2326.

Bauters, T. W. J., Steenhuis, T. S., Parlange, J.-Y., \& DiCarlo, D. A. (1998). Preferential flow in water-repellent sands. SSSA J., 62(5), 1185-1190. https://doi.org/10.2136/sssaj1998.03615995006200050005x

Beven, K. (2018). A century of denial: Preferential and nonequilibrium water flow in soils, 1864-1984. Vadose Zone J., 17(1), article 180153. https://doi.org/10.2136/vzj2018.08.0153

Bob, M. M., Brooks, M. C., Mravik, S. C., \& Wood, A. L. (2008). A modified light transmission visualization method for DNAPL saturation measurements in 2-D models. Adv. Water Resour., 31(5), 727-742. https://doi.org/10.1016/j.advwatres.2008.01.016

Carlyle, G. C., \& Hill, A. R. (2001). Groundwater phosphate dynamics in a river riparian zone: Effects of hydrologic flowpaths, lithology, and redox chemistry. J. Hydrol., 247(3-4), 151-168. https://doi.org/10.1016/S0022-1694(01)00375-4

Conrad, S. H., Glass, R. J., \& Peplinski, W. J. (2002). Bench-scale visualization of DNAPL remediation processes in analog heterogeneous aquifers: Surfactant floods and in situ oxidation using permanganate. J. Contam. Hydrol., 58(1), 13-49. https://doi.org/10.1016/S0169-7722(02)00024-4

Darnault, C. J. G., DiCarlo, D. A., Bauters, T. W., Jacobson, A. R., Throop, J. A., Montemagno, C. D., ... Steenhuis, T. S. (2001).
Measurement of fluid contents by light transmission in transient three-phase oil-water-air systems in sand. Water Resour. Res., 37(7), 1859-1868. https://doi.org/10.1029/2000WR900380

Darnault, C. J. G., Throop, J. A., DiCarlo, D. A., Rimmer, A., Steenhuis, T. S., \& Parlange, J. Y. (1998). Visualization by light transmission of oil and water contents in transient two-phase flow fields. J. Contam. Hydrol., 31(3-4), 337-348. https://doi.org/10.1016/S0169-7722(97)00068-5

Fox, G. A. (2019). Process-based design strengthens the analysis of stream and floodplain systems under a changing climate. Trans. ASABE, 62(6), 1735-1742. https://doi.org/10.13031/trans.13594

Fox, G. A., Muñoz-Carpena, R., \& Purvis, R. A. (2018). Controlled laboratory experiments and modeling of vegetative filter strips with shallow water tables. J. Hydrol., 556, 1-9. https://doi.org/10.1016/j.jhydrol.2017.10.069

Fuchs, J. W., Fox, G. A., Storm, D. E., Penn, C. J., \& Brown, G. O. (2009). Subsurface transport of phosphorus in riparian floodplains: Influence of preferential flow paths. J. Environ. Qual., 38(2), 473-484. https://doi.org/10.2134/jeq2008.0201

Glass, R. J., \& Nicholl, M. J. (1996). Physics of gravity fingering of immiscible fluids within porous media: An overview of current understanding and selected complicating factors. Geoderma, 70(2-4), 133-163. https://doi.org/10.1016/0016-7061(95)00078-X

Glass, R. J., Conrad, S. H., \& Peplinski, W. (2000). Gravitydestabilized nonwetting phase invasion in macroheterogeneous porous media: Experimental observations of invasion dynamics and scale analysis. Water Resour. Res., 36(11), 3121-3137. https://doi.org/10.1029/2000WR900152

Glass, R. J., Parlange, J.-Y., \& Steenhuis, T. S. (1989). Wetting front instability: 1. Theoretical discussion and dimensional analysis. Water Resour. Res., 25(6), 1187-1194. https://doi.org/10.1029/WR025i006p01187

Haber-Pohlmeier, S., Bechtold, M., Stapf, S., \& Pohlmeier, A. (2010). Water flow monitored by tracer transport in natural porous media using magnetic resonance imaging. Vadose Zone J., 9(4), 835-845. https://doi.org/10.2136/vzj2009.0177

Hall, L. D., Gao Amin, M. H., Dougherty, E., Sanda, M., Votrubova, J., Richards, K. S., ... Cislerova, M. (1997). MR properties of water in saturated soils and resulting loss of MRI signal in water content detection at 2 tesla. Geoderma, 80(3-4), 431-448. https://doi.org/10.1016/S0016-7061(97)00065-7

Heijs, A. W. J., Ritsema, C. J., \& Dekker, L. W. (1996). Threedimensional visualization of preferential flow patterns in two soils. Geoderma, 70(2-4), 101-116. https://doi.org/10.1016/0016-7061(95)00076-3

Hoa, N. T. (1981). A new method allowing the measurement of rapid variations of the water content in sandy porous media. Water Resour. Res., 17(1), 41-48. https://doi.org/10.1029/WR017i001p00041

Jarvis, N. J. (2007). A review of non-equilibrium water flow and solute transport in soil macropores: Principles, controlling factors, and consequences for water quality. European J. Soil Sci., 58(3), 523-546. https://doi.org/10.1111/j.13652389.2007.00915.x

Jarvis, N., Koestel, J., \& Larsbo, M. (2016). Understanding preferential flow in the vadose zone: Recent advances and future prospects. Vadose Zone J., 15(12), vzj2016.09.0075. https://doi.org/10.2136/vzj2016.09.0075

Kröckel, L., \& Schmidt, M. A. (2014). Extinction properties of ultrapure water down to deep ultraviolet wavelengths. Opt. Mater. Express, 4(9), 1932-1942. https://doi.org/10.1364/OME.4.001932

Lambrechts, T., Francois, S., Lutts, S., Muñoz-Carpena, R., \& Bielders, C. L. (2014). Impact of plant growth and morphology and of sediment concentration on sediment retention efficiency of vegetative filter strips: Flume experiments and VFSMOD 
modeling. J. Hydrol., 511, 800-810.

https://doi.org/10.1016/j.jhydrol.2014.02.030

Lauvernet, C., \& Muñoz-Carpena, R. (2018). Shallow water table effects on water, sediment, and pesticide transport in vegetative filter strips: Part 2. Model coupling, application, factor importance, and uncertainty. Hydrol. Earth Syst. Sci., 22, 71-87. https://doi.org/10.5194/hess-22-71-2018

Lee, G., Kim, S., \& Kwon, T. (2017). Effect of moisture content and particle size on extinction coefficients of soils using terahertz time-domain spectroscopy. IEEE Trans. Terahertz Sci. Tech., 7(5), 529-535. https://doi.org/10.1109/TTHZ.2017.2731369

Menichino, G. T., Ward, A. S., \& Hester, E. T. (2014). Macropores as preferential flow paths in meander bends. Hydrol. Proc., 28(3), 482-495. https://doi.org/10.1002/hyp.9573

Muñoz-Carpena, R., \& Parsons, J. E. (2004). A design procedure for vegetative filter strips using VFSMOD-W. Trans. ASAE, 47(6), 1933-1941. https://doi.org/10.13031/2013.17806

Muñoz-Carpena, R., Lauvernet, C., \& Carluer, N. (2018). Shallow water table effects on water, sediment, and pesticide transport in vegetative filter strips: Part 1 . Nonuniform infiltration and soil water redistribution. Hydrol. Earth Syst. Sci., 22(1), 53-70. https://doi.org/10.5194/hess-22-53-2018

Muñoz-Carpena, R., Parsons, J. E., \& Gilliam, J. W. (1999). Modeling hydrology and sediment transport in vegetative filter strips. J. Hydrol., 214(1), 111-129. https://doi.org/10.1016/S0022-1694(98)00272-8

Muñoz-Carpena, R., Ritter, A., \& Bosch, D. D. (2005). Field methods for monitoring soil water status. In J. Alvarez-Benedi \& R. Muñoz-Carpena (Eds.), Soil-water-solute process characterization (pp. 167-195). Boca Raton, FL: CRC Press.

Nash, J. E., \& Sutcliffe, J. V. (1970). River flow forecasting through conceptual models: Part I. A discussion of principles. J. Hydrol., 10(3), 282-290. https://doi.org/10.1016/0022-1694(70)90255-6

Niemet, M. R., \& Selker, J. S. (2001). A new method for quantification of liquid saturation in 2D translucent porous media systems using light transmission. Adv. Water Resour., 24(6), 651-666. https://doi.org/10.1016/S0309-1708(00)00045-2

Niemet, M. R., Rockhold, M. L., Weisbrod, N., \& Selker, J. S. (2002). Relationships between gas-liquid interfacial surface area, liquid saturation, and light transmission in variably saturated porous media. Water Resour. Res., 38(8), 10-1-10-12. https://doi.org/10.1029/2001WR000785

Nimmo, J. R. (2010). Theory for source-responsive and free-surface film modeling of unsaturated flow. Vadose Zone J., 9(2), 295306. https://doi.org/10.2136/vzj2009.0085

Oostrom, M., Dane, J. H., \& Wietsma, T. W. (2007). A review of multidimensional, multifluid, intermediate-scale experiments: Flow behavior, saturation imaging, and tracer detection and quantification. Vadose Zone J., 6(3), 610-637. https://doi.org/10.2136/vzj2006.0178

Orozco-López, E., Muñoz-Carpena, R., Gao, B., \& Fox, G. A. (2018). Riparian vadose zone preferential flow: Review of concepts, limitations, and perspectives. Vadose Zone J., 17(1), 180031. https://doi.org/10.2136/vzj2018.02.0031

Rimmer, A., DiCarlo, D. A., Steenhuis, T. S., Bierck, B., Durnford, D., \& Parlange, J. Y. (1998). Rapid fluid content measurement method for fingered flow in an oil-water-sand system using synchrotron x-rays. J. Contam. Hydrol., 31(3-4), 315-335. https://doi.org/10.1016/S0169-7722(97)00070-3

Ritter, A., \& Muñoz-Carpena, R. (2013). Performance evaluation of hydrological models: Statistical significance for reducing subjectivity in goodness-of-fit assessments. J. Hydrol., 480, 3345. https://doi.org/10.1016/j.jhydrol.2012.12.004

Selker, J., Leclerq, P., Parlange, J.-Y., \& Steenhuis, T. S. (1992). Fingered flow in two dimensions: 1 . Measurement of matric potential. Water Resour. Res., 28(9), 2513-2521. https://doi.org/10.1029/92WR00963

Simmons, C. S., \& Keller, J. M. (2005). Liquid spills on permeable soil surfaces: Experimental confirmations. OSTI.Gov. https://doi.org/10.2172/888713

Tidwell, V. C., \& Glass, R. J. (1994). X-ray and visible light transmission for laboratory measurement of two-dimensional saturation fields in thin-slab systems. Water Resour. Res., 30(11), 2873-2882. https://doi.org/10.1029/94WR00953

Wang, H., Chen, X., \& Jawitz, J. W. (2008). Locally calibrated light transmission visualization methods to quantify nonaqueous phase liquid mass in porous media. J. Contam. Hydrol., 102(12), 29-38. https://doi.org/10.1016/j.jconhyd.2008.05.003

Weiler, M., \& Naef, F. (2003). An experimental tracer study of the role of macropores in infiltration in grassland soils. Hydrol. Proc., 17(2), 477-493. https://doi.org/10.1002/hyp.1136

Weisbrod, N., McGinnis, T., Rockhold, M. L., Niemet, M. R., \& Selker, J. S. (2009). Effective Darcy-scale contact angles in porous media imbibing solutions of various surface tensions. Water Resour. Res., 45(10), 1-10. https://doi.org/10.1029/2008WR006957

Weisbrod, N., Niemet, M. R., \& Selker, J. S. (2002). Imbibition of saline solutions into dry and prewetted porous media. $A d v$. Water Resour., 25(7), 841-855. https://doi.org/10.1016/S03091708(02)00038-6

Weisbrod, N., Niemet, M. R., \& Selker, J. S. (2003). Light transmission technique for the evaluation of colloidal transport and dynamics in porous media. Environ. Sci. Tech., 37(16), 3694-3700. https://doi.org/10.1021/es034010m

\section{NOMENCLATURE}

$d=$ total sample thickness $(\mathrm{cm})$

$d_{i}=$ thickness of phase $i$ through the sample $(\mathrm{cm}, i=s$ for sand, $w$ for water, and $a$ for air)

$d_{p}=$ total thickness of pores through the sample $(\mathrm{cm})$

$g=$ acceleration of gravity $\left(\mathrm{cm} \mathrm{s}^{-2}\right)$

$h=$ negative matrix potential (suction) $(-\mathrm{cm})$

$h_{c f}=$ capillary rise characteristic of any porous media $(-\mathrm{cm})$

$h_{w t}=$ height of stationary water table, measured from the bottom of the device $(\mathrm{cm})$

$I=$ light intensity transmitted through a sample of any porous media (-)

$I_{d r y}=$ light intensity under conditions of zero water content (dry) (-)

$I_{i n}=$ light intensity provided by the light source (-)

$I_{\text {log }}=$ relative degree of light transmitted on a logarithmic scale (-)

$I_{\text {res }}=$ punctual matrix of light intensity values under conditions of residual saturation (-)

$I_{s a}=$ point matrix of light intensity values under conditions of complete saturation (-)

$\overline{I_{\text {sat }}}=$ average value of point matrix of light intensity values under conditions of complete saturation (-)

$I_{t}=$ point matrix of light intensity values for each instant $t(\mathrm{~s})$ of drainage of corresponding sand fraction (-)

$I_{\text {resN }}=$ point matrix of normalized light intensity values under wastewater saturation conditions (-)

$I_{t N}=$ point matrix of normalized light intensity values for each instant $t(\mathrm{~s})$ of drainage of corresponding sand fraction (-) 
$I_{w t}=$ point matrix of light intensity values under conditions of residual saturation, with the presence of the phreatic level and capillary rise in stationary conditions (-)

$k=$ number of pores that a beam of light passes through in any porous media (-)

$n_{a, b}=$ refraction coefficient of the individual phases that make up the $j$ th interphase (-) $(j=1$ for sand-water, 2 for water-air, and 3 for sand-air)

$n_{j}=$ quotient between the two refractive indices $\left(n_{a}\right.$ and $\left.n_{b}\right)$ that form the $j$ th interphase (-) $(j=1$ for sand-water, 2 for water-air, and 3 for sand-air)

$p=$ number of pores, filled with water, that a beam of light passes through in any porous media (-)

$r=$ pore radius representative of the porous media under consideration $(\mathrm{cm})$

$S_{e}=$ effective saturation (-)

$S_{e}(x, z, t)=$ point matrix of effective saturation values in an instant $t(\mathrm{~s})$ in the $x, z$ plane (-)

$t=$ time (s)

$V_{t}=$ volume of water present in the system in an instant $t$ (s) $\left(\mathrm{cm}^{3}\right)$

$V_{\text {drain }}=$ total volume drained from the system $\left(\mathrm{cm}^{3}\right)$

$V_{\text {drain }(t)}=$ volume drained from the system in an instant $t(\mathrm{~s})$ $\left(\mathrm{cm}^{3}\right)$

$V_{\text {res }}=$ volume of water in the system under conditions of residual saturation $\left(\mathrm{cm}^{3}\right)$
$V_{\text {sat }}=$ volume of water in the system under conditions of complete saturation $\left(\mathrm{cm}^{3}\right)$

$V_{t}=$ volume of water in the system in an instant $t(\mathrm{~s})\left(\mathrm{cm}^{3}\right)$

$x=$ horizontal coordinate of the $x, z$ plane $\left(\mathrm{cm}^{3}\right.$

$z=$ vertical coordinate of the $x, z$ plane $(\mathrm{cm})$

\section{GREEK LETTERS}

$\alpha_{i}=$ absorption coefficient of phase $i\left(\mathrm{~cm}^{-1}, i=s\right.$ for sand, $w$ for water, and $a$ for air)

$\beta_{i}=$ contact angle between the fluid and capillary of the porous media under consideration (degrees)

$\theta=$ water content in the sample $\left(\mathrm{cm}^{3} \mathrm{~cm}^{-3}\right)$

$\theta_{\text {res }}=$ water content under conditions of residual saturation $\left(\mathrm{cm}^{3} \mathrm{~cm}^{-3}\right)$

$\theta_{\text {sat }}=$ water content under conditions of complete saturation $\left(\mathrm{cm}^{3} \mathrm{~cm}^{-3}\right)$

$\theta(x, z, t)=$ point matrix of humidity values in the $x, z$ plane in an instant $t(\mathrm{~s})\left(\mathrm{cm}^{3} \mathrm{~cm}^{-3}\right)$

$\rho=$ fluid density $\left(\mathrm{g} \mathrm{cm}^{-3}\right)$

$\sigma=$ surface tension of the fluid of the porous media under consideration $\left(\mathrm{g} \mathrm{s}^{-2}\right)$

$\tau_{j}=$ light transmission factor (Fresnel law) corresponding to interphase $j$ ( $j=1$ for sand-water, 2 for water-air, and 3 for sand-air)

$\phi=$ porosity of the sample $\left(\mathrm{cm}^{3} \mathrm{~cm}^{-3}\right)$ 